\title{
Correction to: Wind-induced vibration of structural cables
}

\author{
M. Jafari · F. Hou • A. Abdelkefi
}

Published online: 9 July 2020

(C) Springer Nature B.V. 2020

\section{Correction to:}

\section{Nonlinear Dyn (2020) 100:351-421 https://doi.org/10.1007/s11071-020-05541-6}

The following sentence and both references are incorrectly included in the original article. They do not belong to the published article.

Arena et al. [371] studied the nonlinear dynamic response of a flexible cable through the special Cosserat theory of rods while considering extension, bending, shear stress, and twist effects. They found the proposed model has approximately up to $30 \%$ error within boundary layers to predict the stress value. They also presented the results for several case studies on the taut and shallow cables. In another study, the nonlinearity behavior of overhead cables was evaluated by Barbieri et al. [372] through using the analytical model and finite element technique. The results were compared with experimental data collected by measuring the force under impulsive excitation or electromechanical shaker. Additionally, they found that an increase in

The original article can be found online at https://doi.org/10. 1007/s11071-020-05541-6.

M. Jafari · F. Hou

Aerospace Engineering Department, Iowa State University, Ames, IA 50011, USA

A. Abdelkefi $(\varangle)$

Department of Mechanical and Aerospace Engineering, New Mexico State University, Las Cruces, NM 88003,

USA

e-mail: abdu@nmsu.edu the central sag or fluctuation in tension can change the natural frequency of cable.

Publisher's Note Springer Nature remains neutral with regard to jurisdictional claims in published maps and institutional affiliations. 